Inflammation, Vol. 13, No. 5, 1989

\title{
SURFACE Mo1 (CD11b/CD18) GLYCOPROTEIN IS UP-MODULATED BY NEUTROPHILS RECRUITED TO SITES OF INFLAMMATION IN VIVO
}

\author{
DAVID R. FREYER, ${ }^{1}$ MELVIN L. MORGANROTH, ${ }^{2}$ and \\ ROBERT F. TODD $\mathrm{II}^{3}$ \\ 'Department of Pediatrics and Communicable Diseases \\ Section of Pediatric Hematology/Oncology \\ University of Michigan Medical School \\ ${ }^{2}$ Division of Pulmonary Medicine \\ ${ }^{3}$ Division of Hematology/Oncology \\ Department of Internal Medicine \\ Simpson Memorial Research Institute \\ Ann Arbor, Michigan
}

\begin{abstract}
Inasmuch as the recruitment of polymorphonuclear leukocytes (PMNs) to inflammatory foci in vivo involves adhesion-dependent events (e.g., margination, diapedesis, and directed migration), we sought to characterize the relationship between the local accumulation of PMNs in sterile peritonitis and their surface expression of the adhesion-promoting plasma membrane glycoprotein, Mo1 (CD1lb/ $\mathrm{CD} 18$ ). In an immunofluorescence analysis of PMNs isolated from rats injected intraperitoneally with sterile $1 \%$ glycogen solution, we detected a significant enhancement of surface Mol expression by exudative peritoneal PMNs. In contrast, no significant rise in Mol expression was noted over time by citculating intravascular PMNs (isolated simultaneously). However, these intravascular PMNs had the capacity to inctease their surface Mol density upon exposure to peritoneal fuid supernatant at $37^{\circ} \mathrm{C}$. These results dermonstrate that PMNs at sites of inflammation in vivo do up-modulate their surface expression of the adhesion-promoting Mo1 glycoprotein during their recruitment from the circulating, intravascular lenkocyte pool.
\end{abstract}

\section{INTRODUCTION}

The recruitment of polymorphonuclear leukocytes (PMNs) from the intravascular compartment to extravascular sites of inflammation is a characteristic feature of the acute inflammatory response (reviewed in 1,2). This accumulation of PMNs in vivo, stimulated by soluble chemotactic factors (1-3), appears to 
be accompanied by several cellular activation events including degranulation $(4,5)$ and alterations in cellular responsiveness to stimulated superoxide production $(5,6)$, membrane depolarization (5), and chemotaxis $(5,7-9)$. When enhanced, these effects may in part be due to the up-modulation of surface FMLP receptor expression (5). Another PMN activation event of particular interest in the inflammatory response is the up-modulation of cell surface Mol receptor density. Mol (CD11b/CD18) is a leukocyte plasma membrane glycoprotein that promotes PMN adhesive functions, as demonstrated in vitro by the use of specific inhibitory murine anti-Mol monoclonal antibodies (reviewed in 10), and by the recognition of an inherited disorder in which PMNs from affected persons are deficient in Mol expression and exhibit markedly impaired cellular adhesive functions (reviewed in 10, 11). PMN surface Mo1 expression, in concert with various cellular adhesive properties, is enhanced in vitro in response to exposure to soluble activating factors, including FMLP $(12,13)$, C5a (14-16), $\mathrm{LTB}_{4}(17,18)$, adenine nucleotides (19), PMA, and calcium ionophore A23187 $(12,20,21)$, and others. While it has been suggested that PMN Mo1 receptor up-modulation may occur in vivo $(5,14,22-24)$, little is known about how this up-modulation might relate to the kinetics of PMN recruitment during inflammation.

Therefore, we undertook this study of an animal model of sterile peritonitis to more fully characterize the PMN response to localized acute inflammation, as manifested by the surface expression of the Mol glycoprotein. The results herein demonstrate that there is a rapid, significant, and sustained up-modulation of surface Mol glycoprotein, which accompanies the accumulation of PMNs at sites of inflammation in vivo, lending further support to the notion that PMNs undergo cellular activation during inflammatory recruitment.

\section{MATERIALS AND METHODS}

Reagents. The following reagents were purchased from Sigma Chemical Company (St. Louis, Missouri): ammonium chloride $\left(\mathrm{NH}_{4} \mathrm{Cl}, \mathrm{A4514}\right)$, disodium ethylene-diaminetetraacetate (EDTA, ED2SS), and glycogen type II (derived from oyster, G8751). Sodium bicarbonate $\left(\mathrm{NaHCO}_{3}, 15421\right.$ ) was obtained from Columbus Chemical Industries, Inc. (Columbus, Wisconsin). Fluorescein isothiocyanate-conjugated goat anti-mouse IgG + IgM antibodies were obtained from Tago, Inc. (6253, Burlingame, CA).

Solutions. Phosphate-buffered saline (PBS, without calcium or magnesium) and Duibecco's PBS (DPBS) were mixed according to standard formulations using reagent grade chemicals. $\mathrm{NH}_{4} \mathrm{Cl}$ ery throcyte lysis buffer consisted of $\mathrm{NH}_{4} \mathrm{Cl} 0.15 \mathrm{M}, \mathrm{NaHCO}_{3} 0.01 \mathrm{M}$, and EDTA $0.001 \mathrm{M}$ (adjusted to $\mathrm{pH} 7.20$ ).

Isolation of Peritoneal Elicited and Intravascular PMNs. Pathogen-free, male, outbred Long-Evans rats weighing $400-450 \mathrm{~g}$ were purchased from the Charles River Company (Bar Harbor, Maine). For each experiment, five rats were injected intraperitoneally (under ether anesthesia) 
with $30 \mathrm{ml}$ of sterile $0.9 \% \mathrm{NaCl}$ solution containing $1 \%$ (w/v) glycogen and then allowed to recover from anesthesia. Thereafter, at intervals of $1,2,3,4$, and $\mathrm{I} 6 \mathrm{~h}$ following the injection, one rat was killed (by cardiac puncture under ether anesthesia), its peritoneal cavity opened, and the fluid therein collected and combined with two subsequent peritoneal washings using $0.9 \% \mathrm{NaCl}$ solution. These elicited peritoneal cells were then pelleted, subjected to $\mathrm{NH}_{4} \mathrm{Cl}$ erythrocyte lysis, washed, and resuspended at $10 \times 10^{6} \mathrm{cells} / \mathrm{ml}$ in immunofluorescence wash buffer (21) at $4^{\circ} \mathrm{C}$ prior to staining with monoclonal reagents. Five milliliters of hepatinized whole blood obtained from each rat at the time of cardiac puncture was subjected to $\mathrm{NH}_{4} \mathrm{Cl}$ erythrocyte lysis (one part blood to eight parts $\mathrm{NH}_{4} \mathrm{Cl}$ buffer at $25^{\circ} \mathrm{C}$ for $5-10$ minutes). The leukocytes were then washed twice with PBS and suspended in DPBS prior to in vitro stimulation. Each experiment also included a control animal (anesthetized but not injected with glycogen) from which blood was obtained at time 0 , as described above. Total and differential leukocyte counts were determined morphologically using Wright-Giemsa-stained intravascular and peritoneal specimens. Absolute PMN counts were calculated as the percentage of the total leukocyte count comprising segmented and band forms.

Collection of Peritoneal Fluid Supernatant (PFS). Two tats were injected intraperitoneally with sterile $0.9 \% \mathrm{NaCl}$ solution containing $1 \%$ glycogen, as described above. After $4 \mathrm{~h}$, approximately $15 \mathrm{ml}$ of intraperitoneal fluid were collected from each rat and subjected to high-speed centrifugation to peliet suspended cells. Aliquots of the resulting cell-free PFS were stored at $-80^{\circ} \mathrm{C}$ until used for in vitro stimulation of isolated, intravascular PMNs.

In Vitro Stimulation of PMNs. Isolated leukocytes harvested at each time point were suspended at 4-12 $\times 10^{\%} / \mathrm{ml}$ in DPBS and placed in polypropylene culture tubes (Falcon Plastics, Oxnard, California). Cells were then exposed to an equal volume of undiluted PFS and incubated at $37^{\circ} \mathrm{C}$ for $30 \mathrm{~min}$. Control cells received an equal volume of DPBS and were incubated for 30 min at either $37^{\circ} \mathrm{C}$ or $4^{\circ} \mathrm{C}$. Celis were then diluted in ice-cold PBS, pelleted, and resuspended in immunofluorescence wash buffer (21) prior to further analysis.

Immunofuorescence Analysis. The generation and characterization of munine monoclonal antibodies anti-Mo1 (anti-CD11b, IgM; clone 17) (25) and anti-Mo2 (anti-CD14, IgM; clone 116) (26) have been described. Murine clone 17 anti-(human) Mol cross-reacts with the rat PMN homolog and inhibits rat PMN aggregation (Freyer and Todd, unpublished observations, August 1987). PMNs were subjected to indirect immunofluorescence staining for the expression of the Mal (CD1 lb) antigenic determinant relative to background staining by the isotype-identical negativecontrol antibody, anti-Mo2 (anti-CD14), and examined by flow cytometric analysis as described $(21,27)$. For experiments shown in Table 2 , specific fluorescence intensity represents the computed mean channel number ( $0-230$ channels, linear scale) of cells stained with the anti-Mol reagent minus the mean channel number of cells stained with anti-Mo2 reagent. In Table 2 below, numbers in pareatheses indicate the "-fold" increase in specific fluorescence intensity of either PFS-stimulated intravascular PMNs or elicited peritoneal PMNs, as compared to unstimulated intravascular PMNs maintained at $4^{\circ} \mathrm{C}$. The statistical significance of variations in the absolute PMN counts or in the stimulated increases in specific fiuorescence intensity were evaluated by Student's $t$ test.

\section{RESULTS}

In examining neutrophil responses to localized inflammation in the rat, we first measured the number of PMNs recruited to the peritoneal cavity as a function of time, following the instillation of a local inflammatory agent [sterile $1 \%$ (w/v) glycogen solution]. As shown in Table 1 , there was a profound rise in 
Table 1. Peritoneal, Not Intravascular, PMN Counts are Rapidly Increased in Response to Localized Inflammation ${ }^{a}$

\begin{tabular}{ccc}
\hline & \multicolumn{2}{c}{ Absolute PMN count $^{b}$} \\
\cline { 2 - 3 } Time (hs) & Peritoneal (total) & \multicolumn{1}{c}{ Intravascular (per m) } \\
\hline 0 & & $1.8 \pm 1.3(26.8 \pm 9.5)^{c}$ \\
1 & $2.1 \pm 1.0(34.3 \pm 28.9)^{c}$ & $0.8 \pm 0.3^{d}(12.0 \pm \mathbf{0 . 8})^{c}$ \\
2 & $12.2 \pm 9.1(75.4 \pm 21.6)$ & $2.8 \pm 1.1(31.0 \pm 8.6)$ \\
3 & $50.9 \pm 17.1(98.2 \pm 2.0)$ & $2.7 \pm 0.8(34.2 \pm 10.8)$ \\
4 & $119.3 \pm 80.8(98.4 \pm 2.1)$ & $2.1 \pm 1.2(30.0 \pm 9.7)$ \\
16 & $212.0 \pm 76.3(90.2 \pm 15.0)^{c}$ & $9.5 \pm 7.2^{d}(63.7 \pm 28.7)^{e}$ \\
\hline
\end{tabular}

${ }^{a}$ For each experiment $(N=5)$, five rats were injected intraperitoneally with $30 \mathrm{ml}$ sterile $1 \%$ glycogen solution. Thereafter, at $1,2,3,4$, and $16 \mathrm{~h}$ following the injection, one rat was killed for the collection of accumulated peritoneal and intravascular PMNs, as described in Materials and Methods. Each experiment also included a control animal (not injected with glycogen) from which blood was similarly obtained at time 0 . For all peritoneal and intravascular specimens, total leukocyte counts were determined on cell suspensions examined in a standard hemacytometer, and differential leukocyte counts were determined morphologically using Wright-Giemsa stained slide preparations.

${ }^{b}$ The absolute PMN count (calculated as the percentage of the total leukocyte count comprising segmented and band forms) of peritoneal and intravascular specimens was determined for each time point. Peritoneal values are expressed as the mean total absolute PMN count $\times 10^{6} \pm S D$, and intravascular values as the mean absolute PMN count $\times 10^{6}$ per milliliter of whole blood \pm $S D$. For both, numbers in parentheses represent the mean percentage of PMNs $\pm S D$.

${ }^{c} N=4$.

${ }^{d} \boldsymbol{P}=$ NS (as compared to intravascular PMN count at time 0).

${ }^{e} N=3$.

the mean absolute peritoneal PMN count that was directly related to the duration of the inflammatory exposure. Whereas in normal rats there were negligible numbers of resident peritoneal PMNs (time 0 ), after 1 and $16 \mathrm{~h}$ there were mean total peritoneal PMN counts of 2.1 and $212.0 \times 10^{6}$, respectively, signifying a 100-fold increase over this time interval. In contrast, there was no significant variation over time in the mean intravascular PMN count. Additionally, as shown in Table 1, we observed that within $2-3 \mathrm{~h}$ of intraperitoneal glycogen injection, over $90 \%$ of the accumulated leukocytes were PMNs, whereas the percentage of intravascular PMNs did not vary appreciably over time. These results indicate that in this in vivo model of localized (intraperitoneal) inflammation, there was a rapid, marked, and reproducible accumulation of PMNs that was not accompanied by changes in the PMN count of the circulating, intravascular leukocyte pool.

To assess the relative state of activation of rat PMNs in the intravascular and peritoneal compartments, we examined the surface expression of the $\mathrm{CD} 1 \mathrm{~b} / \mathrm{CD} 18$ (Mo1) glycoprotein, which is an adhesion-promoting molecule 
whose density on the PMN plasma membrane is up-modulated by exposure to infiammatory factors (10) and may play a role in the diapedesis and directed migration of PMNs responding to an inflammatory stimulus. In the immunofluorescence analysis shown in Table 2, surface Mo1 expression by isolated peritoneal PMNs was significantly increased as compared to intravascular PMNs kept unstimulated at $4^{\circ} \mathrm{C}$. This increase in specific fluorescence intensity (SFI) above that of unstimulated intravascular PMNs isolated simultaneously ranged from 4.3- to 8.6-fold over the first $4 \mathrm{~h}\langle P=\mathrm{NS},<0.01,<0.01$, and $<0.05$, for $1,2,3$, and $4 \mathrm{~h}$, respectively) and was of lesser magnitude after $16 \mathrm{~h}$. We detected no significant variation over time in the "baseline" SFI of unstimulated intravascular PMNs. However, as shown in Table 2, these isolated intra-

Table 2. Increased Suface Mo1 Expression is Detected on PMNs Isolated from Inflammatory Focus or Stimulated In Vitro ${ }^{a}$

\begin{tabular}{cccc}
\hline & \multicolumn{3}{c}{ Specific fluorescence intensity $^{b}$} \\
\cline { 2 - 3 } & \multicolumn{2}{c}{ Intravascular PMNs } & Peritoneal PMNs \\
\cline { 2 - 3 } Time (hs) & $4^{\circ} \mathrm{C}$ & PFS-stimulated & $4^{\circ} \mathrm{C}$ \\
\hline 0 & $1.8 \pm 1.3$ & $8.9 \pm 5.6^{c}(4.9)$ & \\
1 & $3.4 \pm 1.8$ & $16.6 \pm 7.7^{d}(4.9)$ & $14.5 \pm 11.4^{e}(4.3)$ \\
2 & $1.9 \pm 1.2$ & $8.6 \pm 5.4^{f}(4.5)$ & $13.1 \pm 6.4^{d}(4.5)$ \\
3 & $2.3 \pm 1.7$ & $12.1 \pm 6.9^{f}(5.3)$ & $12.1 \pm 5.0^{d}(5.3)$ \\
4 & $1.6 \pm 1.1$ & $10.3 \pm 4.9^{d}(6.4)$ & $13.8 \pm 9.2^{f}(8.6)$ \\
16 & $5.5 \pm 5.1^{8}$ & $15.0 \pm 10.4(2.7)$ & $8.6 \pm 5.3(1.6)$ \\
\hline
\end{tabular}

${ }^{a}$ Peritoneal and intravascular PMNs $(N=5)$ were collected as described in Table 1 , footnote $a$. Isolated peritoneal PMNs were maintained at $4^{\circ} \mathrm{C}$, whereas isolated intravascular PMNs were either kept at $4^{\circ} \mathrm{C}$ or exposed to cell-free peritoneal fluid supematant (PFS, prepared in Materials and Methods) at $37^{\circ} \mathrm{C}$ for $30 \mathrm{~min}$. PMNs were then stained by indirect immunofluorescence for the expression of the Mol (CD1 b) determinant, relative to the background staining by an isotypeidentical negative-control antibody.

${ }^{b}$ Values represent the mean specific fluorescence intensity $\pm S D(0-230$ channels, linear scale) of cells stained by anti-Mo1 antibody; nonspecific background staining by the negative-control antibody has been subtracted in each case. Photomultip iar tube setting was $1000 \mathrm{mV}$ in all experiments. Numbers in parentheses represent the -fold uncrease of specific fluorescence intensity of either peritoneal PMNs $\left(4^{\circ} \mathrm{C}\right.$ ) or intravascular PMNs exposed to PFS at $37^{\circ} \mathrm{C}$ for $30 \mathrm{~min}$, above that of intravascular PMNs maintained at $4^{\circ} \mathrm{C}$. The corresponding relative increase in surface Mol expression stimulated by warming of intravascular PMNs in the absence of PFS was 2.7-, $2.4-, 3.4-3.1-, 2.6-$, and 2.3 -fold at $0,1,2,3,4$, and $16 \mathrm{~h}$, respectively.

${ }^{c} P=0.05$.

${ }^{d} P<0.01$

${ }^{e} P=\mathrm{NS}$.

$f_{P}<0.05$.

${ }^{8}$ While there was a tendency for intrasvacular PMNs isolated at $16 \mathrm{~h}$ to exhibit higher than baseline (time 0) surface Mol expression (which could indicate delayed intravascular PMN activation), the difference did not reach statistical significance $(P=\mathrm{NS})$. 
vascular PMNs, when exposed to peritoneal fluid supernatant (PFS) in vitro at $37^{\circ} \mathrm{C}$ for $30 \mathrm{~min}$, could up-modulate their surface Mol antigen density to levels that approached or exceeded those of peritoneal PMNs isolated simultaneously. This stimulated enhancement of Mol expression by PFS-exposed intravascular PMNs averaged 5.2-fold above that of circulating PMNs kept at $4{ }^{\circ} \mathrm{C}$ (significant $0-4 \mathrm{~h}$ ), with a lesser increase stimulated after $16 \mathrm{~h}$. Isolated intravascular PMNs incubated in buffer alone at $37^{\circ} \mathrm{C}$ for $30 \mathrm{~min}$ (in the absence of PFS) exhibited an intermediate enhancement of Mo1 expression (Table 2, footnote b). Collectively, these results demonstrate that an increase in the surface expression of the Mol adhesion glycoprotein is a feature characteristic of PMNs recruited from the intravascular leukocyte pool to sites of acute inflammation.

\section{DISCUSSION}

Since the accumulation of PMNs at sites of inflammation in vivo is dependent upon several adhesion-related processes (e.g., margination, diapedesis, and directed migration), in this study we sought to characterize the relationship between the inflammatory recruitment of PMNs and their surface expression of the adhesion-promoting plasma membrane glycoprotein, Mo1. Mo1 (CD11b/ CD18; CR3; gp 155,95) is a member of the CD11/CD18 family of structurally related heterodimers expressed on the surfaces of PMNs and certain mononuclear phagocytes (10) and has been shown to promote multiple cellular adhesive interactions, including PMN adherence and spreading on artificial $(25,28)$ and cellular $(29,30)$ substrates, aggregation $(14,28,29)$, chemotaxis $(25,28)$, and binding of C3bi-opsonized particles (31-33) and gram-negative bacteria (34). The Mol glycoprotein exists in an intracellular pool associated with secondary and/or tertiary granules $(16,20,35)$ and is rapidly translocated to the plasma membrane upon exposure of the cell to a variety of activating factors [e.g., FMLP (12, 13), C5a (14-16), $\operatorname{LTB}_{4}(17,18)$, ATP (19), PMA and A23187 $(12,20,21)$, and others], thus serving as an "activation marker" for PMNs.

We have found that PMNs accumulating at sites of acute inflammation in vivo do indeed significantly up-modulate their surface density of the Mol antigen, as compared to intravascular PMNs isolated simultaneously from the same animal. Moreover, we have shown that this enhancement occurs rapidly (within $1 \mathrm{~h}$ of recruitment), is sustained with further local recruitment of PMNs, and is not accompanied by significant elevations of either the Mol expression or the total count of intravascular PMNs. Thus, our findings extend the observations of Zimmerli et al. (5), who reported a twofold increase in surface Mol expression by exudative guinea pig and human PMNs analyzed at a single time point (14 h) following the introduction of an inflammatory stimulus. 
Since Mol up-modulation coincided with PMN accumulation at the site of peritoneal inflammation, we evaluated the possibility that the administration of specific anti-Mo1 monoclonal antibody might interfere with this process. However, when a similar group of rats were pretreated ( $1 \mathrm{mg}$ intravenously $1 \mathrm{~h}$ before glycogen injection) with a murine anti-human Mo1 antibody (clone 17 producing an IgM antibody cross-reacting with the rat homolog), there was no significant reduction in intraperitoneal PMN accumulation $4 \mathrm{~h}$ after glycogen injection (despite the presence of saturating concentrations of anti-Mol antibody in the plasma and peritoneal fluid), as compared to negative control rats receiving no antibody (113 \pm 10 vs. $106 \pm 5 \times 10^{6}$, respectively; mean total peritoneal PMN count $\pm S D, N=3$ ). This is in contrast to the findings of Rosen and Gordon (36), who recently reported a $75 \%$ inhibition of myelomonocytic cell accumulation in a murine model of sterile peritonitis where mice were pretreated with an anti-Mol antibody. The discrepancy in these results is most likely due to a difference in epitope recognition in which one antibody but not the other competitively binds to a region of the Mol glycoprotein that promotes PMN adhesive interactions critical to inflammatory recruitment in vivo $(25,28,29)$. The importance of the CD11/CD18 family of adhesion glycoproteins in PMN migration to inflammatory foci has been indicated by the inhibitory effects of other CD11/CD18-specific monoclonal reagents in several additional animal models of acute inflammation (37-41).

While some degree of surface Mol expression is required for normal PMN adhesive function in the inflammatory response, the functional importance of the increase in receptor density above baseline exhibited by activated cells is unclear. The physiologic significance of enhanced Mo1 expression is suggested by its detection in the settings of clinically active systemic lupus erythematosus (22), hemodialysis leukopenia (14), severe burns (23), and the treatment of cancer patients with intravenous GM-CSF (24). However, a series of recent observations suggest that qualitative, rather than quantitative, changes in existing plasma membrane Mo1 receptors could underlie the enhanced cellular adhesiveness observed in stimulated PMNs. Wright and coworkers reported the activation and deactivation of CR3 (Mo1) binding activity in human PMNs and monocytes without a corresponding change in receptor number $(42,43)$. More recently, Vedder and Harlan described increased adherence of human PMNs to cultured endothelial cell monolayers that was independent of the enhancement of CD11b or CD18 determinants detected on PMNs stimulated by PMA, A23187, or FMLP (44). In addition, Buyon et al. reported that maximal FMLPstimulated aggregation of human PMNs did not correspond to increases in surface Mol expression (45). Examples of qualitative changes in the Mol receptor that might confer functional responsiveness include topographic clustering of CR3 receptors on the plasma membrane $(46,47)$ or glycoprotein phosphorylation $(43,48)$. Thus, the well-documented inhibitory effect of certain anti-Mo1 
monoclonal reagents on the recruitment of PMNs to inflammatory foci in vivo (36-41) could be due to an interference with such qualitative changes. If true, the enhancement of Mo1 expression by PMNs recruited during inflammation, as reported here, may serve a purpose yet to be elucidated.

Acknowledgments-The authors are grateful for the technical assistance of Ms. Sue O. Schoeneich in harvesting rat specimens, and Ms. Clare E. Rogers and Ms. Marcia Ananich in performing flow cytometric studies. Expert secretarial support was provided by Ms. Tracy Lockhart. The work was supported by NIH granis CA39064 (R.F.T.), HL07622 (D.R.F.), and HL01595 (M.L.M.).

\section{REFERENCES}

1. MaLech, H. L., and J. I. GaLLIN. 1987. Current concepts; Immunology, neutrophils in human diseases. N. Engl. J. Med. 317:687.

2. Boxer, G. J., J. T. CurnutTe, and L. A. Boxer. 1985. Polymorphonuclear leukocyte function. Hosp. Pract. 20:69.

3. Gallin, J. I., D. G. Wright, H. L. Malech, J. M. Davis, M. S. Klempner. and C. H. KIRKPATRJCK. 1980. Disorders of phagocyte chemotaxis. Ann. Intern. Med. 92:520.

4. WRIGHT, D. G., and J. I. GALLIN. 1979. Secretory responses of human neutmphils: Exocytosis of specific (secondary) granules by human neutrophils during adherence in vitro and during exudation in vivo. J. Immunol. 123:285.

5. Zimmerli, W., B. SeligmanN, and J. I. Gallin. 1986. Exudation primes human and guinea pig neutrophils for subsequent responsiveness to the chemotactic peptide $N$-formylmethionylleucylphenylalanine and increases complement component $\mathrm{C}$ bi receptor expression. $J$. Clin. Invest. 77:925.

6. Zimmerli, W., P. D. Lew, H. J. Cohen, and F. A. Waldvogel. 1984. Comparative superoxide-generating system of granulocytes from blood and peritoneal exudates. Infect. Immunol. 46:625.

7. Charon, J. A., Z. Metzger, J. T. Hoffeld, C. Oliver, J. I. Gallin, and S. E. MergenHAGEN. 1982. An in vitro study of neutrophils obtained from normal gingival sulcus. $J$. Periodont. Res. 17:614.

8. Davis, J. M., P. DineEn, and J. I. Gallin. 1980. Neutrophil degranulation and abnomal chemotaxis after thermal injury. J. Immunol. 124:1467.

9. Turner, R. A., H. R. Schumacher, and A. R. Myers. 1973. Phagocytic function of polymorphonuclear leukocytes in rheumatic diseases. J. Clin. Invest. 52:1632.

10. Tond, R. F., III, and D. R. Freyer. 1988. The CD11/CD18 leukocyte glycoprotein deficiency. Hematol. Oncol. Clin. North Am. 2:13.

11. ANDERson, D. C., and T. A. SpRTnger. 1987. Leukocyte adhesion deficiency: An inherited defect in the Mac-1, LFA-1, and p150,95 glycoproteins. Annu. Rev. Med. 32:175.

12. ARnaout, M. A., H. SPITS, C. TeRhorst, J. PitT, and R. F. Todd, III. 1984. Deficiency of a leukocyte surface glycoprotein (LFA-1) in two patients with Mol deficiency: Effect of cell activation on Mo1/LFA-1 surface expression in nomal and deficient leukocytes. J. Clin. Invest. 74:1291.

13. Berger, M. , J. O'SheA, A. S. Cross, T. M. Folks, T. M. Chused, E. J. Brown, and M. M. 
Frank. 1984. Human neutrophils increase expression of C3bi as well as C3b receptors upon activation. J. Clin. Invest. 74:1566.

14. ARnaout, M. A., R. M. HAKIM, R. F. Todd, III, N. Dana, and H. R. Colten. 1985. Increased expression of an adhesion-promoting surface glycoprotein in the granulocytopenia of hemodialysis. N. Engl. J. Med. 312:457.

15. Yancey, K. B., J. O'Shea, T. Chused, E. Brown, T. Takahashi, M. M. Frank, and T. J. LAWLEY. 1985. Human C5a modulates monocyte $\mathrm{FC}$ and $\mathrm{C3}$ receptor expression, J. Immunol. 135:465.

16. O'Shea, J. J., E. J. Brown, B. E. Seligmann, J. A. Metcalf, M. M. Frank, and J. I. GALLIN. 1985. Evidence for distinct intracellular pools of receptors for $\mathrm{C} 3 \mathrm{~b}$ and $\mathrm{C} 3 \mathrm{bi}$ in human neutrophils. J. Immunol. 134:2580.

17. Miller, L. J., D. F. Bainton, N, Borregard, and T. A. Springer, 1987. Stimulated mobilization of monocyte Mac- 1 and $\mathrm{p} 150,95$ adhesion proteins from an intracellular vesicular compartment to the cell surface. J. Clin. Invest. 80:535.

18. Berger, M., D. L. BirX, E. M. Wetzler, J. J. O'Shea, E. J. Brown, and A. S. Cross. 1985. Calcium requirements for increased complement receptor expression during neutrophil activation. J. Immunol. 135:1342.

19. Freyer, D. R., L. A. BOXeR, R. A. AXTELl, and R. F. TODD, III. 1988. Stimulation of human neutrophil adhesive properties by adenine nucleotides. J. Immunol. 141:580.

20. Todd, R. F., III, M. A. Arnadout, R. E. Rosin, C. A. Crowley, W. A. Peters, and B. A. BABIoR. 1984. Subcellular localization of the large subunit of Mol (Mol $\alpha$; formerly gp 110) a surface glycoprotein associated with neutrophil adhesion. J. Clin. Invest. 74:1280.

21. Freyer, D. R., M. L. Morganroth, C. E. Rogers, M. A. ARnadout, and R. F. Todd, III. 1988. Modulation of surface CD11/CD18 glycoproteins (Mo1, LFA-1, and p150,95) by human mononuclear phagocytes. Clin. Immunol. Immunopathol. 46:272.

22. Buyon, J. P., N. Shadick, R. Berkman, P. Hopkins, J. Dalton, G. Weissmann, R. WinCHESTER, and S. B. ABRAMSON. 1988. Surface expression of Gp165/95, the complement receptor CR3, as a matker of disease activity in systemic lupus erythematosis. Clin. Immunol. Immunopathol. 46:141.

23. Moore, F. D., Jr., C. Davis, M. Rodertck, J. A. Mannick, and D. T. Fearon. 1986. Nentrophil activation in thermal injury as assessed by increased expression of complement receptors. N. Engl. J. Med. 314:948.

24. Socinski, M. A., S. A. Cannistra, R. Sullivan, A. Elias, K. Antman, L. Scumipper, and J. D. GRIFFIN. 1988. Granulocyte-macrophage colony-stimulating factor induces the expression of the CD11b surface adhestion molecule on human granulocytes in vivo. Blood 72:619.

25. Dana, N., B. Styrt, J. D. Griffin, R. F. Todd, II, W. S. Klempner, and M. A. ARnaout. 1986. Two functional domains in the phagocyte membrane glycoprotein Mol identified with monoclonal antibodies. J. Immutuol. 137:3259.

26. TODD, R. F., III, L. M. NaDLER, and S. F. SChlossman, 1981. Antigens on human monocytes identified by monoclonal antibodies. J. Immunol. 126:1435.

27. Todd, R. F., Ill, P. A. Alvarez, D. A. BrotT, and D. Y. Liv. 1985. Bacterial lipopolysaccharide, phorbol myristate acetate, and muramyl dipeptide stimulate the expression of human monocyte surface antigen, Mo3e. J. Immunol. 135:3869.

28. Anderson, D. C., L. J. Miller, F. C. Schmalstieg, R. Rothlein, and T. A. Springer. 1986. Contributions of the Mac-1 glycoprotein family to adherence-dependent granulocyte functions: Structure-function assessments employing subunit-specific monoclonal antibodies. J. Immunol. 137:15.

29. Wallis, W. J., D. D. Hickstein, B. R. Schwartz, C. H. June, H. D. Ochs, P. G. Beatty, S. J. KLeBANOFF, and J. M. HARLAN. 1986. Monoclonal antibody-defined functional epitopes 
on the adhesion-promoting glycoprotein complex (CDw18) of human neutrophils. Blood 67:1007.

30. Simon, R. H., P. D. DeHart, and R. F. Todd, III. 1986. Neutrophil-induced injury of rat pulmonary alveolar epithelial cells. J. Clin. Invest. 78:1375.

31. Arnaout, M. A., R. F. Todd, III, N. Dana, J. Melamed, S. F. Schlossman, and H. R. COLTEN. 1983. Inhibition of phagocytosis of complement C3- or immunoglobulin G-coated particles and of $\mathrm{C} 3$ bi binding by monoclonal antibodies to a monocyte-granulocytc membrane glycoprotein (Mo1). J. Clin. Invest. 72:171.

32. Beller, D. I., T. A. Springer, and R. D. Schreiber. 1982. Anti-Mac-1 selectively inhibits the mouse and human type three complement receptor. J. Exp. Med. 156:1000.

33. Wright, S. D., P. E. Rao, W. C. Van Voorhis, L. S. Craigmyle, K. Iida, M. A. Talle, E. F. WestberG, G. Goldstein, and S. C. Silverstein. 1984. Identification of the C3bi receptor of human monocytes and macrophages by using monoclonal antibodies. Proc. Natl. Acakl. Sci. U.S. A. 80:5699.

34. WRIGHT, S. D., and M. T. C. JoNG. 1986. Adhession-promoting receptors on human macrophages recognize Escherichia coli by binding to lipopolysaccharide. J. Exp. Med. 164:1876.

35. Petrequin, P. R., R. F. Tond, III, J. Devall, L. A. Boxer, and J. T. Curnutte. 1987. Association between gelatinase release and increased plasma membrane expression of the Mo1 glycoprotein. Blood 69:605.

36. Rosen, H., and S. Gordon. 1987. Monoclonal antibody to the murine type 3 complement receptor inhibits adhesion of myelomonocytic cells in vitro and inflammatory cell recruitment in vivo. J. Exp. Med. 166:1685.

37. Arfors, K.-E., C. Lundberg, L. Lindbom, K. Luneberg, P. G. Beatty, and J. M. HarLAN. 1986. A monoclonal antibody to the membrane glycoprotein complex CD18 inhibits polymorphonuclear leukocyte accumulation and plasma leakage in vivo. Blood 69:338.

38. PRICE, T. H., P. G. BeATTY, and S. R. CorPuz. 1987. In vivo inhibition of neutrophil function in the rabbit using monoclonal antibody to CD18. J. Immunol. 139:4174.

39. Simpson, P. J., R. F. Todd, III, J. C. Fantone, J. K. Mickelson, J. D. GRiffin, and B. R. LUCCHESI. 1988. Reduction of experimental canine myocardial reperfusion injury by a monoclonal antibody (anti-Mo1, anti-CD11b) that inhibits letkocyte adhesion. $J$. Clin. Invest. $81: 624$.

40. Vedder, N. E., R. K. Winn, C. L. Rice, E. Y. Chi, K.-E. Arfors, and J. M. Harlan. 1988. A monoclonal antibody to the adherence-promoting leukocyte glycoprotein, CD18, reduces organ injury and improves survival from hemorhagic shock and resuscitation in rabbits. J. Cin. Invest. 81:939.

41. Hernandez, L. A., M. B. Grisham, B. Twohig, K.-E. Arfors, J. M. Harlan, and D. N. GRANGER. 1987. Role of neutrophils in ischemia-reperfusion-induced mictovascular injury. Am. J. Physiol. 253:H699.

42. Wright, S. D., P. A. Detmers, M. T. C. Jong, and B. C. Meyer. 1986. Interferon- $\gamma$ depresses binding of ligand by $\mathrm{C} 3 \mathrm{~b}$ and $\mathrm{C} 3 \mathrm{bi}$ receptors on cultured human monocyles, an effect reversed by fibronectin. J. Exp. Med. 163:1245.

43. WRIGHT, S. D., and B. C. MEYer. 1986. Phorbol esters cause sequential activation and deactivation of complement receptors on polymorphonuclear leukocytes. J. Immunol. 136:1759.

44. VEDDER, N. B., and J. M. HARLAN. 1988. Increased surface expression of CD11b/CD18 (Mac1) is not required for stimulated neutrophil adherence to cultured endothelium. J. Clin. Invest. 81:676.

45. Buyon, J. P., S. B. Abramson, M. R. Philips, S. G. Slade, G. D. Ross, G. Weissmann, and R. J. WINCHESTER. 1988. Dissociation between increased surface expression of Gp165/ 95 and homotypic neutrophil aggregation. J. Immunol. 140:3156. 
46. Petty, H. R., J. W. Francis, R. F. Todd, II, P. Petrequn, and L. A. Boxer, 1987. Neutrophil C3bi receptors: Formation of membrane clusters during cell triggering requires intracellular granules. J. Cell Physiol. 133:1.

47. Detmers, P. A., S. D. Wrigirt, E. Olser, B. Kimbald, and Z. Cohn. 1987. Aggregation of complement receptors on human neutrophils in the absence of ligands. J. Cell Biol. 105:1137.

48. HARA, T., and S. M. Fu. 1986. Phosphorylation of $\alpha, \beta$ subunits of $180 / 100-\mathrm{Kd}$ polypeptides (LFA-1) and related antigens. In Leukocyte Typing II, Vol. 3, Human Mycloid and Hematopoietic Cefls. E. L. Reinherz, B. F. Haynes, L. M. Nadler, and I. D. Bernstein, editors. Springer-Verlag, New York. 74-84. 